Journal of Management and Bussines (JOMB)

Volume 1, Nomor 1, Juni 2019

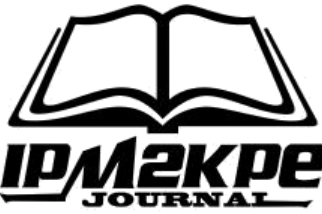

p-ISSN : 2656-8918

e-ISSN: $2684-8317$

DOI : https://doi.org/10.31539/jomb.v1i1.608

\title{
KEKUATAN KEUNIKAN PRODUK DAN WORD OF MOUTH TERHADAP KEPUTUSAN PEMBELIAN
}

\author{
Ibnu Agung Permana ${ }^{1}$, Asep M. Ramdan², Faizal Mulia $Z^{3}$ \\ Universitas Muhammadiyah Sukabumi ${ }^{1,2,3}$ \\ Email: ibnupermana1417@ gmail.com ${ }^{1}$
}

\begin{abstract}
ABSTRAK
Tujuan penelitian ini adalah untuk mengetahui keunikan produk dan word of mouth terhadap keputusan pembelian pada UMKM bibika ambon sugema Sukabumi. Metode penelitian yang digunakan oleh penulis dalam penelitian ini menggunakan metode sistem random sampling dimana penulis menyebarkan kuisioner terhadap 75 konsumen. Teknik analisis yang digunakan penulis adalah menggunakan teknik analisis regresi linear berganda, koefesien korelasi ganda dan koefesien determinasi. Dan untuk pengujian hipotesis penulis menggunakan uji statistik secara parsial (uji t) dan uji simultan (uji f). Hasil penelitian menggunakan uji koefesien determinasi menunjukan nilai (Adjuster $\mathrm{R}^{2}$ ) sebesar 0,749 yang berarti pengaruh keunikan produk dan word of mouth terhadap keputusan pembelian adalah $76 \%$ dan $24 \%$ dipengaruhi oleh faktor lain yang tidak diteliti. Selain itu, pengujian koefesien korelasi ganda menunjukan nilai $\mathrm{R}$ sebesar 0,869 yang berarti terjadi hubungan yang kuat antara keunikan produk dan word of mouth terhadap keputusan pembelian. Berdasarkan hasil uji $\mathrm{F}$ yang telah dilakukan, ditemukan nilai sig. $0,000<0,05$. Simpulan, keunikan produk dan word of mouth berpengaruh signifikan secara parsial terhadap keputusan pembelian.
\end{abstract}

Kata Kunci : Keunikan Produk, Word Of Mouth, Keputusan Pembelian.

\section{ABSTRACT}

The purpose of this study was to determine the uniqueness of the product and word of mouth towards purchasing decisions at the UMKM UMKM Sukugumi Sugema UMKM. The research method used by the authors in this study used a system of random sampling where the authors distributed questionnaires to 75 consumers. The analysis technique used by the writer is using multiple linear regression analysis techniques, multiple correlation coefficient and determination coefficient. And to test the hypothesis the author uses a partial statistical test ( $t$ test) and a simultaneous test ( $f$ test). The results of the study using the determination coefficient test shows the value (Adjuster R2) of 0.749 which means the influence of product uniqueness and word of mouth on purchasing decisions is $76 \%$ and $24 \%$ influenced by other factors not examined. In addition, testing multiple correlation coefficients shows an $R$ value of 0.869 , which means there is a strong relationship between product uniqueness and word of mouth towards purchasing decisions. Based on the results of the $F$ test that has been done, the sig value is found. 0,000 <0,05. Conclusions, product uniqueness and word of mouth partially have a significant effect on purchasing decisions.

Keywords: Product Uniqueness, Word Of Mouth, Purchasing Decision. 


\section{PENDAHULUAN}

Topik penelitian mengenai keputusan pembelian peneliti mengkaji, Selama 20 tahun terakhir. Berdasarkan datanya (Henthorne, LaTour and Hudson, 1997), (Lin and o Chen, 2006), (Shukla, 2009), (Hanaysha, 2018). Kementerian Koperasi dan Usaha Kecil dan Menengah Republik Indonesia Melalui Badan Pusat Statistik (BPS), Menjelaskan bahwa pada tahun 2017 Jumlah UMKM yang ada di Indonesia mencapai 62.922.617 Juta, Angka ini naik 2,06\% dari tahun sebelumnya yang berjumlah 61.651.177. Di tahun 2017, UMKM mampu menyerap 116.673.416 juta tenaga kerja yang dimana angka ini juga naik sebesar 3,41\% dibandingkan tahun sebelumnya. Berdasarkan adanya penelitian mengenai keputusan pembelian pada literatur dengan data dari berbagai industri, serta pada sektor UMKM (Mulyadi 2015), (Nugraha, Suharyono dan Kusumawati, 2015), (Karima, 2017), (Permada, 2018).

Menjamurnya Usaha Mikro Kecil dan Menengah khususnya dalam bidang kuliner dengan berbagai inovasi baik dari rasa, kemasan maupun bentuknya membuat persaingan bisnis di bidang kuliner sangat kompetitif sehingga para pengusaha atau pelaku dalam industri kuliner harus berfikir mengenai produk seperti apa yang harus mereka buat melalui ide yang segar sehingga dampaknya saat ini banyak sekali kulinerkuliner yang mungkin belum pernah kita tahu sebelumnya baik dari nama maupun bentuknya, padahal mungkin saja itu adalah kuliner yang sudah ada sebelumnya akan tetapi dibuat dengan cara yang unik sehingga tampilannya tampak asing bagi yang melihatnya Sarosa (Siregar, 2011).

Pemenuhan kebutuhan konsumen terutama pada bidang kuliner tentunya menjadi perhatian perusahaan yang bergerak disana, karena produk yang dapat bersaing tadi jika memiliki keunikan tentu akan membuat konsumen penasaran akan produk tersebut. Akan tetapi standar konsumen dalam memilih produk pada saat ini sudah sangat berbeda, Tradisionalitas pada sebuah produk baik dari kemasan, rasa maupun bentuk juga mampu menjadikan daya tarik bagi konsumen dalam persaingan usaha di bidang kuliner. Perusahaan sebisa mungkin memahami bahwa dalam mengambil keputusan, ada beberapa hal yang dipertimbangkan oleh konsumen seperti bentuk produk, rasa dari produk maupun kemasan produk sebelum akhirnya melakukan keputusan pembelian Schiffman dan kanuk (Pratiwi, 2017) 
Permasalahan yang sering dihadapi oleh pelaku UMKM terutama dalam bidang kuliner terletak pada keputusan pembelian, Sebelum membeli produk konsumen biasanya memiliki preferensi terhadap produk yang akan mereka pilih baik dari bentuk, rasa maupun banyaknya variant tersebut. Permasalahan yang terjadi pada konsumen ialah mereka belum sama sekali mengetahui seperti apa produk baru yang akan mereka beli sehingga cenderung memilih produk yang sudah jelas baik dari rasa dan juga bentuk produknya. Selain itu, sulitnya mencari informasi terhadap produk UMKM tersebut menjadi sebab konsumen enggan melakukan pembelian. Banyaknya produk yang sejenis membuat konsumen ragu dengan produk baru sejenis yang muncul karena mereka khawatir jika nantinya setelah membeli produk tidak sesuai dengan harapan dan manfaat yang mereka rasakan ketika membeli produk tersebut.

Tema yang di ajukan ialah Kekuatan Keunikan Produk dan Word Of Mouth terhadap Keputusan Pembelian pada UMKM Bibika Ambon Sugema Sukabumi. Penelitian ini bertujuan untuk mengukur pengaruh keunikan produk dan word of mouth terhadap keputusan pembelian pada UMKM Bibika Ambon Sugema Sukabumi. Kelebihan penelitian ini dari penelitian sebelumnya yaitu, dalam penelitian ini variabel Keunikan Produk dan Word Of Mouth diuji secara simultan maupun parsial terhadap Keputusan Pembelian.

\section{KAJIAN TEORI}

\section{Keunikan Produk}

Keunikan produk adalah supplier yang memproduksi produk yang sangat spesifik agar perusahaan memiliki posisi tawar yang lebih tinggi dibandingkan dengan perusahaan yang produknya merupakan produk komoditas (Kartono dalam Poli, Kindangen, Ogi, 2015). Ada 3 Keunikan pada produk agar dapat membentuk sebuah nilai positif bagi produk tersebut, diantaranya:

1. Bentuk Produk. Bentuk produk merupakan pola yang didalamnya menyangkut berbagai hal seperti bentuk fisik, model, warna, ukuran dan lainnya dengan maksud memberikan kemudahan bagi konsumen dalam mengidentifikasi produk yang unik sehingga akan memperkuat identitas produk tersebut.

2. Rasa Produk. Rasa merupakan respon dari apa yang dirasakan konsumen melalui panca indranya terutama jika produk yang dikonsumsi, lidah akan merespon rasa dari 
produk tersebut baik manis, pahit, asin, asam dan pedas. Jika suatu produk memiliki rasa yang unik saat pertama kali konsumen merasakan produk tersebut maka produk tersebut akan dapat memenuhi kepuasan.

3. Kemasan/Penyajian Produk. Penyajian produk biasanya bertujuan untuk melindungi sebuah produk agar tidak rusak, namun jika dibuat unik, penyajian produk ataupun kemasan dengan menarik dapat membuat konsumen tertarik sehingga memutuskan untuk membelinya.

Hubungan keunikan produk terhadap keputusan pembelian menurut (Poli, Kindangen \& Ogi, 2015) menyatakan bahwa, keunikan produk berpengaruh signifikan terhadap keputusan pembelian.

\section{Word Of Mouth}

Word Of Mouth adalah tindakan konsumen memberikan informasi kepada konsumen lain dari seseorang kepada orang lain (antar pribadi) non komersial baik merek, produk (Ali Hasan dalam Putri, 2016) Selain itu, Word Of Mouth juga merupakan komunikasi tidak hanya menghubungkan konsumen dengan produsen tetapi juga menghubungkan konsumen dengan lingkungan sosialnya, yaitu komunikasi pemasaran yang berasal dari perusahaan dan berasal dari konsumen. Word Of Mouth juga merupakan usaha pemasaran yang memicu pelanggan untuk membicarakan, mempromosikan, merekomendasi, dan menjual suatu produk, jasa, atau merek kepada pelanggan lain

Mikkelsen (Lubis, 2014) Menjelaskan bahwa indikator Word Of Mouth dapat diukur dengan cara berikut : 1) kemauan konsumen dalam membicarakan hal-hal positif tentang kualitas produk kepada orang lain (Delight Effect); 2 konsumen merekomendasikan produk pada orang lain (emotional Effect); 3) dorongan terhadap teman atau relasi untuk melakukan transaksi atas produk (Inspirational Effect)" Hubungan word of mouth terhadap keputusan pembelian menurut (Ibrahim, 2017) menyatakan bahwa "Word of Mouth berpengaruh secara positif dan signifikan terhadap keputusan pembelian konsumen". 


\section{Keputusan Pembelian}

Keputusan Pembelian adalah pemilihan dari dua jenis atau lebih alternatif pilihan putusan pembelian Schiffman dan kanuk (Rahmi, 2017) Sementara itu, keputusan pembelian adalah tahap dalam proses pengambilan keputusan pembeli dimana konsumen benar-benar membeli (Kotler \& Armstrong 2016).

Menurut Kotler \& Keller (Rismayadi, 2018) tahapan dalam proses pengambilan keputusan pembelian terdiri dari lima tahap, yaitu :

1. Pengenalan Masalah. Hal ini muncul ketika konsumen mulai mengenali masalah dalam pemenuhan kebutuhan yang dirasa tidak sesuai dengan apa yang dia harapkan. Sehingga perusahaan menggali informasi mengenai apa saja yang dibutuhkan oleh konsumen dalam memenuhi kebutuhan tersebut agar membangkitkan minat konsumen dalam membeli produk tersebut.

2. Pencarian Informasi. Konsumen yang mulai merasa butuh akan hal tersebut akan berusaha mencari informasi mengenai produk yang dapat memenuhi kebutuhannya.

3. Evaluasi Alternatif, yaitu konsumen memiliki beberapa alternatif dalam pemilihan produk dimana produk yang dipilih dilihat dari harapan konsumen mengenai produk tersebut. Adapun pemilihan lain dilakukan atas dasar manfaat yang paling besar dirasakan oleh konsumen tersebut setelah menggunakan produk.

4. Keputusan Pembelian. Pada tahap evaluasi, konsumen akan membuat preferensi pada merek-merek tertentu yang telah dikumpulkan lalu akan memilih produk sesuai dengan pilihan konsumen tersebut yang dirasa paling memiliki manfaat ataupun yang paling mereka sukai.

5. Prilaku Pasca membeli. Konsumen akan mengalami pengalaman baik itu kepuasan pasca membeli produk atau ketidakpuasan atas pembelian produk tersebut dan melakukan evaluasi terhadap produk yang telah dibelinya sesuai dengan pengalaman tersebut.

\section{METODE PENELITIAN}

Penelitian ini dilaksanakan di UMKM Bibika Ambon Sugema Sukabumi dengan menggunakan metode sampling dengan teknik samplingnya yaitu simple random sampling dan melakukan penyebaran kuesioner terhadap 75 konsumen Bibika Ambon Sugema Sukabumi. Teknik analisis yang digunakan dalam penelitian ini yaitu 
teknik analisis regresi berganda dan melakukan pengujian hipotesis secara Simultan (Uji

F) dan juga parsial (Uji t).

\section{Hasil Analisis Regresi Linear Berganda}

Regresi linear berganda berguna untuk meneliti seberapa besar pengaruh beberapa variabel yang berkorelasi dengan variabel yang diuji. Berikut ini merupakan hasil dari regresi linear berganda yang ditunjukan pada tabel 1 :

Tabel 1

Hasil Uji Regresi Linear Berganda

\begin{tabular}{|c|c|c|c|c|c|c|}
\hline \multicolumn{7}{|c|}{ Coefficients $^{\mathrm{a}}$} \\
\hline & \multirow[b]{2}{*}{ Model } & \multicolumn{2}{|c|}{$\begin{array}{c}\text { Unstandardized } \\
\text { Coefficients }\end{array}$} & \multirow{2}{*}{$\begin{array}{c}\text { Standardized } \\
\text { Coefficients } \\
\text { Beta }\end{array}$} & \multirow[b]{2}{*}{$\mathrm{t}$} & \multirow[b]{2}{*}{ Sig. } \\
\hline & & B & $\begin{array}{l}\text { Std. } \\
\text { Error }\end{array}$ & & & \\
\hline \multirow[t]{3}{*}{1} & (Constant) & 3.963 & 1.775 & & 2.232 & .029 \\
\hline & $\begin{array}{c}\text { Keunikan Produk } \\
\text { (X1) }\end{array}$ & .495 & .122 & .353 & 4.046 & .000 \\
\hline & $\begin{array}{l}\text { Word Of Mouth } \\
\text { (X2) }\end{array}$ & 1.287 & .195 & .574 & 6.584 & .000 \\
\hline
\end{tabular}

a. Dependent Variable: Keputusan Pembelian

Sumber : Data Primer (Kuesioner), 2019

Dari hasil uji regresi linear berganda diatas, dapat diperoleh persamaan sebagai berikut :

$$
Y=3,963+0,495 X_{1}+1,287 X_{2}
$$

\section{Koefesien Determinasi $\left(\mathbf{R}^{2}\right)$}

Tabel 2

Hasil Koefesien Determinasi

\begin{tabular}{lcccc}
\hline \multicolumn{4}{c}{ Model Summary } \\
\hline Model & $\mathrm{R}$ & R Square & $\begin{array}{c}\text { Adjusted R } \\
\text { Square }\end{array}$ & $\begin{array}{c}\text { Std. Error of the } \\
\text { Estimate }\end{array}$ \\
\hline 1 & $.869^{\mathrm{a}}$ & .756 & .749 & 2.00894 \\
\hline a. Predictors: (Constant), Word Of Mouth (X2), Keunikan Produk (X1) \\
\hline Sumber : Data Primer (Kuesioner), 2019
\end{tabular}

Hasil tabel 2 menunjukan besarnya nilai Adjusted $\mathrm{R}^{2}$ adalah 0,749; Hal tersebut menunjukan $76 \%$ variabel keputusan pembelian dapat dijelaskan oleh kedua variabel independen yaitu Keunikan Produk dan Word Of Mouth Sementara 24\% berasal dari faktor yang tidak diteliti dalam penelitian. 


\section{Koefesien Korelasi Ganda (R)}

Tabel 3

Hasil Koefesien Korelasi Ganda

\begin{tabular}{lcccc}
\hline \multicolumn{4}{c}{ Model Summary } \\
\hline Model & $\mathrm{R}$ & R Square & $\begin{array}{c}\text { Adjusted R } \\
\text { Square }\end{array}$ & $\begin{array}{c}\text { Std. Error of the } \\
\text { Estimate }\end{array}$ \\
\hline 1 & $.869^{\mathrm{a}}$ & .756 & .749 & 2.00894 \\
\hline a. Predictors: (Constant), Word Of Mouth (X2), Keunikan Produk (X1) \\
\hline Sumber : Data Primer (Kuesioner), 2019
\end{tabular}

Berdasarkan tabel 3 diatas diperoleh angka $\mathrm{R}$ Sebesar 0,869 berada pada kategori 0,80-1,000. Hal ini menunjukan bahwa hubungan yang terjadi antara keunikan produk dan word of mouth dengan keputusan pembelian sangat kuat.

\section{Uji Signifikasi Secara Simultan (Uji F)}

Tabel 4

Hasil Uji F

\begin{tabular}{|c|c|c|c|c|c|c|}
\hline Model & & $\begin{array}{l}\text { Sum Of } \\
\text { Squares }\end{array}$ & $\mathrm{df}$ & Mean Square & $\mathrm{F}$ & Sig. \\
\hline \multirow[t]{3}{*}{1} & Regression & 900.006 & 2 & 450.003 & 111.502 & $000^{b}$ \\
\hline & Residual & 290.580 & 72 & 4.036 & & \\
\hline & Total & 1190.587 & 74 & & & \\
\hline
\end{tabular}

a. Dependent Variable : Keputusan Pembelian (Y)

b. Predictors : (Constant), Word Of Mouth (X2), Keunikan Produk (X1)

Sumber : Hasil Pengolahan Data Kuesioner, 2019

Berdasarkan tabel 4 diatas, hasil uji $\mathrm{F}$ yang dilakukan dapat diperoleh nilai sig. $0,000<0,05$; nilai $\mathrm{F}_{\text {hitung }} 111,502>\mathrm{F}_{\text {tabel }} 2,38$. Hasil ini menunjukan bahwa keunikan produk dan word of mouth berpengaruh secara simultan terhadap keputusan pembelian.

\section{Uji Signifikasi Secara Parsial (Uji t)}

Tabel 5

Hasil Uji t

\begin{tabular}{|c|c|c|c|c|c|c|}
\hline \multicolumn{7}{|c|}{ Coefficients $^{\mathrm{a}}$} \\
\hline \multirow{2}{*}{\multicolumn{2}{|c|}{ Model }} & $\begin{array}{r}\mathrm{Un} \\
\mathrm{C}\end{array}$ & $\begin{array}{l}\text { dardized } \\
\text { icients }\end{array}$ & $\begin{array}{c}\text { Standardized } \\
\text { Coefficients }\end{array}$ & \multirow[b]{2}{*}{$\mathrm{t}$} & \multirow[b]{2}{*}{ Sig. } \\
\hline & & B & Std. Error & Beta & & \\
\hline \multirow[t]{3}{*}{1} & (Constant) & 3.963 & 1.775 & & 2.232 & .029 \\
\hline & Keunikan Produk & .495 & .122 & .353 & 4.046 & .000 \\
\hline & Word Of Mouth & 1.287 & .195 & .574 & 6.584 & .000 \\
\hline
\end{tabular}

Sumber : Hasil Pengolahan Data Kuesioner, 2019 
Berdasarkan tabel 5 diatas, hasil uji t yang dilakukan pada variabel keunikan produk menghasilkan nilai dengan sig. 0,000 < 0,05; nilai $t_{\text {hitung }} 4,046>t_{\text {tabel }} 1,66629$, nilai tersebut menunjukan bahwa keunikan produk berpengaruh signifikan secara parsial terhadap keputusan pembelian. Variabel word of mouth memiliki nilai sig. 0,000 < 0,05; nilai $\mathrm{t}_{\text {hitung }} 6,584>\mathrm{t}_{\text {tabel }} 1,66629$, artinya word of mouth berpengaruh positif dan signifikan terhadap keputusan pembelian.

\section{PEMBAHASAN}

Keunikan produk berpengaruh secara positif dan signifikan terhadap keputusan pembelian (Y) secara parsial. Hal ini berdasarkan hasil pengujian $\mathrm{t}$ yang menunjukan nilai sig. $0,000<0,05$; nilai $\mathrm{t}_{\text {hitung }} 4,046>\mathrm{t}_{\text {tabel }} 1,66629$, maka dapat disimpulkan bahwa $\mathrm{H}_{\mathrm{a}}$ diterima dan $\mathrm{H}_{0}$ ditolak. Hal ini menunjukan bahwa keunikan produk yang ada di perusahaan memberikan nilai positif dalam mempengaruhi keputusan pembelian konsumen.

Word of mouth berpengaruh secara positif dan signifikan terhadap keputusan pembelian (Y) secara parsial. Hal ini dibuktikan dengan hasil pengujian $\mathrm{t}$ yang menunjukan nilai sig. $0,000<0,10$; nilai $t_{\text {hitung }} 6,584>\mathrm{t}_{\text {tabel }} 1,66629$, maka dapat disimpulkan bahwa $\mathrm{H}_{\mathrm{a}}$ diterima dan $\mathrm{H}_{0}$ ditolak. Hal ini menunjukan bahwa word of mouth yang dilakukan oleh sesama konsumen memberikan nilai positif dalam mempengaruhi keputusan pembelian konsumen lain.

Keunikan produk dan word of mouth berpengaruh positif dan signifikan terhadap keputusan pembelian (Y) secara simultan. Hal ini dibuktikan dengan hasil pengujian $\mathrm{F}$ menunjukan nilai sig. $0,000<0,05$; nilai $F_{\text {hitung }} 111,502>F_{\text {tabel }} 2,38$, dari hasil tersebut dapat disimpulkan bahwa $\mathrm{H}_{\mathrm{a}}$ diterima dan $\mathrm{H}_{0}$ ditolak. Hal ini menunjukan bahwa keunikan produk dan word of mouth berpengaruh signifikan secara simultan terhadap keputusan pembelian.

Berdasarkan dari hasil yang didapat melalui analisis regresi berganda uji $\mathrm{F}$ dengan tingkat signifikasi sebesar 0,05 (5\%) menunjukan bahwa variabel Keunikan Produk $\left(\mathrm{X}_{1}\right)$ dan Word Of Mouth $\left(\mathrm{X}_{2}\right)$ berpengaruh secara simultah terhadap Keputusan Pembelian (Y). Hal tersebut ditunjukan dengan hasil nilai sig. 0,000 $<0,05$ dan nilai $\mathrm{F}_{\text {hitung }} 116,214>\mathrm{F}_{\text {tabel }} 2,38$. Nilai Koefesien Determinasi $\left(\mathrm{R}^{2}\right)$ diperoleh hasil yang menunjukan variabel Keunikan Produk $\left(\mathrm{X}_{1}\right)$ dan Word Of Mouth $\left(\mathrm{X}_{2}\right)$ mempengaruhi 
sebesar 0,749 (76\%) terhadap Keputusan Pembelian (Y), dan 24\% dipengaruhi oleh faktor yang tidak di teliti dalam penelitian. Dari hasil tersebut dapat disimpulkan bahwa konsumen akan memutuskan membeli produk tersebut jika bentuk, rasa dan kemasan produk sesuai dengan harapan mereka mengenai produk yang unik. Selain itu produk yang unik akan memberikan kesan berbeda dari barang yang sama pada umumnya dan akan membuat konsumen melakukan pembelian. Informasi mengenai produk yang didapat konsumen juga mempengaruhi mereka dalam melakukan pembelian, rekomendasi dan juga ajakan dari orang lain terhadap produk tersebut membuat konsumen memutuskan untuk melakukan pembelian terhadap produk UMKM Bibika Ambon Sugema Sukabumi.

Berdasarkan hasil yang didapat melalui analisis data pada uji t Keunikan Produk $\left(\mathrm{X}_{1}\right)$ dengan Keputusan Pembelian (Y) menunjukan bahwa nilai $\mathrm{t}_{\text {hitung }}$ sebesar 4,046 sedangkan $t_{\text {tabel }}(\alpha=0,10)$ diperoleh hasil $t_{\text {tabel }} 1,66629$. Nilai signifikasi yang didapat $0,000<0,05$ dan nilai $\mathrm{t}_{\text {hitung }} 4,046>\mathrm{t}_{\text {tabel }} 1,66629$, maka pengaruh $\left(\mathrm{X}_{1}\right)$ terhadap (Y) signifikan. Dari hasil tersebut dapat disimpulkan bahwa Keunikan Produk berpengaruh secara signifikan terhadap Keputusan Pembelian. Hal ini menunjukan bahwa saat konsumen membeli produk, Keunikan Produk yang didapat melalui bentuk, rasa dan kemasan produk menjadi alasan konsumen dalam melakukan pembelian terhadap produk UMKM Bibika Ambon Sugema Sukabumi.

Berdasarkan hasil analisis yang dilakukan dengan menggunakan teknik uji t pada variabel Word Of Mouth (X2) dengan Keputusan Pembelian (Y) menunjukan bahwa nilai thitung sebesar 6,584 sedangkan ttabel $(\alpha=0,10)$ diperoleh hasil ttabel 1,66629. Nilai signifikasi yang didapat $0,000<0,05$ dan nilai thitung 6,584 > ttabel 1,66629, maka pengaruh (X2) terhadap (Y) signifikan. Dari hasil tersebut dapat disimpulkan bahwa word of mouth berpengaruh secara signifikan terhadap keputusan pembelian. Hal ini menunjukan bahwa informasi mengenai produk yang disampaikan orang lain mengenai produk dapat mempengaruhi konsumen dalam melakukan keputusan pembelian, selain itu rekomendasi dan ajakan untuk membeli produk juga mempengaruhi konsumen dalam melakukan pembelian pada produk UMKM Bibika Ambon Sugema Sukabumi. 


\section{SIMPULAN}

Kesimpulan dari penelitian ini menunjukan bahwa Variabel Keunikan Produk dan Word Of Mouth berpengaruh positif dan signifikan secara simultan terhadap Keputusan Pembelian. Keunikan Produk juga berpengaruh positif dan signifikan secara parsial terhadap Keputusan pembelian. Dan Word Of Mouth juga berpengaruh positif dan signifikan secara parsial terhadap Keputusan Pembelian.

\section{DAFTAR PUSTAKA}

Aliftsa Ibrahim, (2017), Pengaruh Word Of Mouth terhadap Keputusan Pembelian (Studi Pada Konsumen Waroeng Steak And Shake JLN.Banteng No.14 Bandung), 4(2)

Budi Rismayadi, (2018), Pengaruh Brand Equity Terhadap Keputusan Pembelian Produk Sepeda Motor Yamaha Vixion : Studi Kasus di Universitas Singaperbangsa Karawang, 10(4)

Citra Aprilliani Putri, Handoyo Djoko W \& Sari Listyorini, (2016), Pengaruh Kualitas Layanan, Kualitas Produk, dan Word Of Mouth Communication Terhadap Keputusan Pembelian pada RM Garang Asem Sari Rasa, 5(1).

Ervina Siregar (2011), Analisis Keunikan Produk Yang Mempengaruhi Terciptanya Word Of Mouth Pada Produk Es Krim Magnum Classic (Studi Kasus Pada Mahasiswa FISIP USU).

Finnan Aditya Aji Nugraha, Suharyono, Andriani Kusumawati, (2015), Pengaruh Word Of Mouth Terhadap Keputusan Pembelian dan Kepuasan Pembelian (Studi pada Konsumen Kober Mie Setan jalan Simpang Soekarno-Hatta nomor 1-2 Malang), 22(1).

Gugun Mulyadi, (2015), Pengaruh Merek dan Kemasan terhadap Keputusan Pembelian produk UMKM, 2(1).

Jalal Rajeh Hanaysha, (Oktober 2017), An examination of the factors affecting consumer's purchase decision in the Malaysian retail market.

Kotler, Philip and Kevin Lane Keller, (2016): Marketing Management, 15th Edition New Jersey: Pearson Pretice Hall, Inc.

Kresna Aji Permada, (2018), Analisis Strategi Positioning terhadap Keputusan Pembelian Konsumen di Greens Production, 5(2).

Long-Yi Lin \& Chun-Shuo Chen, (2006), The influence of the country-of-origin image, product knowledge and product involvement on consumer purchase decisions: an empirical study of insurance and catering services in Taiwan, 23(5).

Paurav Shukla, (2009), Impact of contextual factors, brand loyalty and brand switching on purchase decisions, 26(5).

Rini Dwi Martha Lubis, (2014), Pengaruh Keunikan Produk terhadap terciptanya Word Of Mouth pada produk burger (Studi kasus pada Usaha "Rumah Burger" jln. Medan area Selatan-Medan.

Sekar Muthia Karima, (2017), Pengaruh Harga, Kualitas Produk, Citra Merek dan Kesadaran Merek terhadap Keputusan Pembelian pada batik pasha di UMKM Center Semarang. 
Tony L Henthorne, Michael S LaTour and Tim W. Hudson, (1997), Japanese couples' marital roles in stages of product purchase decision making, 14(1).

Vocke Poli, Paulus Kindangen, Imelda Ogi, (2015), Analisis Pengaruh Kualitas, Promosi dan Keunikan Produk Terhadap Keputusan Pembelian Souvenir Amanda Collection, 15(5).

Yuly Rahmi Pratiwi, (2017), Pengaruh Word Of Mouth Communication Terhadap Keputusan Pembelian Konsumen Pada Boardgame Lounge Smart Cafe Pekanbaru, 4(1). 